\title{
LA HISTORIA SOCIAL DE HUASCA DE OCAMPO Y EL PROGRAMA PUEBLOS MÁGICOS
}

\section{THE SOCIAL HISTORY OF HUASCA DE OCAMPO AND THE PUEBLOS MÁGICOS PROGRAM}

\author{
Mario Alberto VELÁZQUEZ GARCÍA ${ }^{1}$ \\ Fabiola BAUTISTA MOEDANO ${ }^{2}$
}

\begin{tabular}{|lll|}
\hline Recibido & $:$ & 01.12 .2020 \\
Aceptado & $:$ & 06.01 .2021 \\
Publicado & $:$ & 12.02 .2021 \\
\hline
\end{tabular}

RESUMEN: En este artículo presentamos un análisis de la vida social de algunos de las personas y lugares que caracterizan a la población mexicana Huasca de Ocampo, Hidalgo. El objetivo del estudio es mostrar los cambios que se producen en una población específica, pero también en la sociedad nacional, cuando se valoran, usan y comercializan lugares para el turismo alejados de su identidad cultural, generando un producto que resulta alejado de las creencias y vida cultural de la población que habita dichos espacios. En este caso, una localidad contemplada en el programa federal Pueblos Mágicos del gobierno federal mexicano.

Palabras clave: historia social de los objetos, pueblos mágicos, Huasca, México.

\begin{abstract}
In this article we present an analysis of the social life of some of the people and places that characterize the Mexican population Huasca de Ocampo, Hidalgo. The objective of the study is to show the changes that occur in a specific population, but also in national society, when places are valued, used and commercialized for tourism, generating a product that is far removed from the beliefs and cultural life of the population that inhabits these spaces. The objective of the study is to show the changes that occur in a specific population, but also in national society, when places for tourism are valued, used and commercialized far from their cultural identity. In this case, a locality included in the federal program Pueblos Mágicos of the Mexican federal government.
\end{abstract}

Keywords: social history of objects, magical towns, Huasca, Mexico.

\footnotetext{
${ }^{1}$ Doctor en Sociología. El Colegio del Estado de Hidalgo. Estado de Hidalgo-México. Email: mvelazquez@elcolegiodehidalgo.edu.mx. ORCID: https://orcid.org/0000-0001-9869-2188

${ }^{2}$ Maestría en Planeación y Desarrollo Regional. El Colegio del Estado de Hidalgo. Estado de Hidalgo-México. Email: mpdr0119@elcolegiodehidalgo.edu.mx. ORCID: https://orcid.org/0000-0002-7588-8695
} 


\section{INTRODUCCIÓN}

El turismo, en su forma de actividad económica contemporánea, convierte los espacios sociales donde se desarrolla en escenarios donde un grupo de personas trabaja proveyendo servicios y actuaciones para los visitantes. En las pequeñas localidades, esto tiene como resultado un creciente distanciamiento o enajenación de las comunidades frente a los lugares, festividades, comidas y la historia que anteriormente constituían su identidad; celebraciones como día de muertos son convertidas en un espectáculo donde las familias son rodeadas por visitantes que fotografían o filman sus actos como si se tratara de una representación con el único fin de satisfacerlos, los platillos locales son reconvertidos y "suavizados" para ser del agrado de los turistas y ser .ofrecidos en restaurantes a los cuales los mismos pobladores locales que crearon este tipo de comida no pueden acceder por sus altos precios.

Este artículo pretende producir una historia social de los elementos que constituyen el paisaje de una comunidad mexicana que forma parte del programa federal "Pueblos Mágicos". El generar una historia social busca mostrar los cambios que se producen en una población específica, pero también en la sociedad nacional, cuando se valoran, usan y comercializan lugares, festividades, vidas de personajes históricos, entre otros. Esto implica que no presentaremos una mera lista de bienes y datos, sino una reconstrucción histórico-social de algunos de los elementos que configuran a la comunidad de Huasca de Ocampo.

Los estudios sobre turismo y paisaje generalmente dan por "dados" los edificios, espacios, personajes o festividades que son considerados como "históricos", "atractivos", "particulares" y "bellos". Sin embargo, no siempre es así, en diversas ocasiones un edificio, un canal de agua o fábrica que tuvo una importancia fundamental en un punto específico de la historia de una localidad puede perder su trascendencia después de algún acontecimiento económico o político, o simplemente, ser olvidados por los pobladores al punto de caer en el abandono y ser finalmente destruidos. Por otro lado, también existen edificaciones o celebraciones que son apenas conservadas por un conjunto de personas y que posteriormente de la filmación de una película, la realización de un estudio o una lucha social (Velázquez, 2010), se convierten en un centro de peregrinaje quede cientos de personas quieren aspiran conocer. Estos cambios en la valoración de un lugar o actividad humana constituyen una parte de lo que podemos entender cómo la vida social de los objetos (o lugares) (Velázquez, 2010; Appadurai, 1991). Este tipo 


\section{Journal of the Academy $|143|$}

de investigaciones subraya la importancia de incidir en el cómo el turismo afecta la supervivencia cultural de lugares específicos como Huasca de Ocampo, México.

El estudio de la vida social de los objetos y los lugares no tiene únicamente un objetivo de aumentar el conocimiento sobre espacios y personajes de una localidad específica como Huasca de Ocampo (México), todo lo contrario, tiene al menos tres potenciales aplicaciones: 1) permite aplicar la propuesta teórica-metodológica de la vida social de los objetos al análisis de los bienes patrimoniales y turísticos; 2) para la comunidad local, contribuye a la revalorización de los bienes que han sido artificialmente separados o incluso ignorados en el proceso de construcción de su identidad frente al crecimiento de la actividad turística; 3) para la planeación del turismo, permite colocar en el centro de esta acción al gobierno y a la comunidad local mediante la recuperación de su identidad por medio de investigaciones como esta, que no buscan beneficiar al turista sino a los habitantes del lugar que será visitado.

De manera inicial, presentaremos la conceptualización teórica sobre la vida social de los lugares. En este sentido, la vida social comprende las etapas mercantiles de los objetos, es decir, el periodo cuando buscan ser intercambiadas o consumidas, que, en el caso específico del turismo, no solo son compradoras sino visitadas por los turistas. Posteriormente daremos algunos datos generales sobre Huasca de Ocampo a fin de que exista una idea precisa sobre qué sus características económicas, sociales y poblacionales tiene. A continuación, presentaremos la vida social de algunos de los bienes culturales y personas relevantes que habitaron Huasca de Ocampo. Como dijimos antes, el objetivo es demostrar que algunos de los elementos centrales en la formación de una localidad pueden ser parcialmente olvidados, incluso dentro de un contexto como el crecimiento de la actividad turística, donde parecería existir una búsqueda por todo aquello que haga de un lugar algo "único" y con historias sociales. En último lugar, presentaremos las conclusiones generales.

Los datos aquí presentados son parte de una investigación de largo aliento realizada en conjunto con la Secretaría de Turismo de Hidalgo sobre aquellas localidades de esta entidad que participan en el programa Pueblos Mágicos. Los datos aquí utilizados fueron recabados de fuentes primarias y secundarias. Respecto a las primeras, cabe mencionar la realización de investigación participativa en diversos periodos durante los últimos cuatro años en Huasca de Ocampo. Durante este lapso se han llevado a cabo entrevistas formales e informales con miembros del ayuntamiento, prestadores de servicios turísticos, turistas y habitantes locales. 


\section{Journal of the Academy | 144 |}

La selección de los lugares o personas sobre las cuales desarrollamos su vida social corresponde con aquellos que fueron considerados como los atractivos "únicos" que permitieron a esta localidad ingresar al programa Pueblos Mágicos. La excepción es el caso de León Trotsky, el cual introducimos para mostrar la existencia de relatos locales que no corresponden con una cierta narrativa turística diseñada por el gobierno nacional y local.

\section{DESARROLLO}

\section{El programa Pueblos Mágicos}

Pueblos Mágicos constituye una política federal que comenzó a operar en el 2001, con la incorporación de 30 localidades en todo el país. La primera localidad en ser considerada fue Huasca de Ocampo, Hidalgo. El objetivo central de esta acción de gobierno es el fomento de la infraestructura turística en pequeñas localidades, la diversificación de los productos turísticos y la promoción de nuevos destinos cercanos a las grandes concentraciones urbanas.

Los recursos financieros del programa están destinados a la conservación del patrimonio histórico y arquitectónico de las localidades, la mejora de la imagen urbana y la creación de servicios relacionados con el turismo, como hoteles, por ejemplo. El Programa Pueblos Mágicos busca consolidar la diversificación de la oferta turística mexicana, pues ésta se concentraba en regiones y ciudades particulares. El gobierno federal de Vicente Fox (20002012) consideró que en distintas partes de México existía el potencial para generar focos turísticos, partiendo de ampliar la definición sobre esta actividad y pasando del llamado turismo de "sol y playa" para darle un mayor peso al turismo cultural (Velázquez y Labra, 2015, p. 4647).

En un plano general, podemos decir que el programa Pueblos Mágicos ha tenido resultados ambiguos: fortalece la infraestructura turística (hoteles y restaurantes), en las localidades que participaron, en un promedio de $148 \%$ y genera un incremento en los recursos municipales, en promedio de 234\% (Velázquez y Clausen, en prensa). Sin embargo, el programa presenta una serie de problemáticas: 1) Falta de coherencia entre las medidas tomadas y las políticas generales sobre turismo; 2) Poca cooperación entre las instituciones del programa, municipios, estados y federación en materia turística; 3) Los gobiernos estatales y municipales no realizan una inversión complementaria, de forma que los recursos federales son insuficientes para 


\section{Journal of the Academy $|145|$}

consolidar una localidad como turística; 4) Existen problemas en la operación de los comités de los Pueblos Mágicos (SECTUR, 2016); y 5). La promoción y el fomento para la comercialización de los bienes culturales de las localidades no son acompañados de apoyos y programas de cultura, por lo que se está generando una mercantilización y separación entre la población local y sus manifestaciones culturales.

No obstante, Pueblos Mágicos es una de las políticas de turismo más exitosa en México, (como dijimos antes) por el crecimiento en infraestructura y recursos municipales que genera, pero también por su continuidad, - ha funcionado durante 19 años dentro de cuatro administraciones federales provenientes de partidos de derecha, centro e izquierda (Partido Acción Nacional, Partido Revolucionario Institucional y Movimiento Regeneración Nacional). La permanencia de este programa hace fundamental los análisis sobre este tipo de políticas públicas, particularmente respecto a las consecuencias que su operación genera a nivel local, y particularmente en los bienes culturales.

\section{La vida social de las cosas y los lugares}

El valor de las mercancías encierra uno de los temas centrales en el nacimiento y desarrollo de la economía, sin embargo, poco seguimiento se ha dado desde esta ciencia social a la trayectoria total que tiene una mercancía. En las últimas décadas, la antropología y la sociología han generado un área de investigación conocida como "la vida social de los objetos", objetos como el dinero, las bebidas, el café y diversas mercancías han sido analizadas desde el cómo se volvieron objeto de interés, intercambio, pero también los distintos significados que su consumo, uso, almacenamiento y su misma existencia representa para las distintas sociedades y épocas (Appadurai, 1991; Burns, 2004; Cowan, 2005; Dood, 2014).

Como propone Arjun Appadurai en La vida social de las cosas, el valor y el intercambio de las mercancías y los objetos (es decir las cosas que no fueron creadas pensando en ser intercambiadas en alguna forma de mercado) no queda delimitado por el trabajo o los elementos que contienen, sino por una serie de interacciones, imaginarios y valoraciones sociales que son cambiantes y dinámicas, de tal manera, que una misma mercancía puede tener un valor grande o pequeño en el momento de su creación pero tomar posteriormente un valor exponencialmente mayor (o menor) con el paso de los años. Una forma entonces de realizar el análisis de la vida social de las cosas es analizar la situación mercantil, entendiendo por esta 


\section{Journal of the Academy $|146|$}

como "la situación en la cual su intercambiabilidad (pasada, presente o futura) por alguna otra cosa se convierta en su característica socialmente relevante" (Appadurai, 1991: 29).

Para Appadurai existen tres elementos que componen la situación mercantil de una mercancía: 1) la fase mercantil de la vida social de cualquier cosa, esta hace referencia al hecho de que las mercancías entran y salen del mercado de intercambios y que este periodo puede ser muy breve, largo, terminal, reversible, normativamente desarrollado o producirse de maneras desviadas o excluyentes 2) la candidatura mercantil, que hace referencia a los estándares y criterios (simbólicos, clasificatorios y morales) que son la base para definir o no, la que tan intercambiables son las cosas dentro de un contexto social, territorial e histórico determinado. Estas candidaturas mercantiles se producen también entre grupos que no comparten marcos culturales, por lo que pueden existir distintos "regímenes de valor" con supuestos y estándares para la clasificación de las mercancías, y 3) el contexto mercantil donde puede colocarse el objeto, y que comprende las distintas arenas sociales dentro (o entre) unidades culturales que permiten conectar la candidatura mercantil de las cosas con su fase mercantil. Es decir, son aquellos tipos de actos o instituciones sociales (las bodas arregladas por los padres, la subasta de obras de arte, entre otras) que resaltan y se enfocan en la parte mercantil de los objetos o las relaciones (Appadurai, 1991).

Una segunda división de las mercancías que resulta de utilidad para entender la vida social de los objetos se refiere a la propuesta por Jacques Marquet: 1) mercancías por destino, que engloban aquellas cuyos productores elaboraron pensando en su intercambio; 2) mercancías por metamorfosis, cosas que tenían un uso distinto y son llevadas a una condición de venta; 3 ) mercancías por desviación, estas constituyen un caso especial de las de metamorfosis, son los objetos que en su elaboración fueron específicamente y particularmente protegidas de su comercialización; 4) ex mercancías, son aquellos objetos que fueron retirados temporal o permanentemente del intercambio y son situadas de nuevo dentro del mismo (Maquet, 1986).

Una última división que resulta útil para analizar la vida social de las cosas es propuesta por Appadurai (1991) y comprende a las mercancías "homogéneas" y las "singulares". Las primeras son aquellas que son producidas de una manera masiva, estandarizada e indistinguible una de otra, mientras la segunda hace referencia a aquellos objetos cuya calidad descansa precisamente en sus particularidades y características únicas dentro de algún grupo específico (Appadurai, 1991). 
En el caso del turismo, la reconstrucción de la historia social de las cosas nos permite entender cómo es que algunos lugares, personajes y festividades han sido utilizados para mercantilizar una localidad específica, en el caso específico de Huasca de Ocampo, dentro de un programa federal mexicano denominado Pueblos Mágicos. Pero al mismo tiempo, la historia social nos permite ver la brecha existente entre el relato para la construcción de la candidatura mercantil por parte de las autoridades y comercios interesados en promover el turismo frente a los relatos, valoraciones y usos de los pobladores locales. Aunque ambos grupos pueden compartir la importancia sobre ciertos lugares o festividades, muy frecuentemente existen espacios, personajes, festividades y comidas que son altamente apreciadas por los locales, pero que no son promovidas turísticamente.

\section{Características del lugar}

El municipio de Huasca de Ocampo se sitúa en la parte sureste del estado de Hidalgo, comprendiendo su extensión territorial en total $305.80 \mathrm{~km} 2$, a una altura de 2100 metros sobre el nivel del mar y a 34 kilómetros de la ciudad de Pachuca de Soto. Dicho municipio tiene sus colindancias al norte con el municipio de Huayacocotla del estado de Veracruz, al sur con el municipio de Omitlán de Juárez, Epazoyucan y Singuilucan, al oriente con el municipio de Acatlán, y al poniente con Omitlán de Juárez y Atotonilco el Grande, todos correspondientes al estado de Hidalgo (Agenda de Competitividad Turística, 2014). En el año 2015, Huasca de Campo contaba con una población de 17728 habitantes de los cuales 8,363 son hombres y 9,365 mujeres. De acuerdo con proyecciones del Consejo Nacional de Población (CONAPO), para el año 2020 la población en el municipio alcanza los 19362 habitantes, en donde el grueso de su población (12 401 habitantes) se ubica entre los 15 y 64 años (CONAPO, Proyecciones de la Población de México, 2010-2050) (Gobierno del Estado de Hidalgo, 2016).

\section{El nombre del lugar: Huasca de Ocampo}

Una de las primeras maneras de entender la vida social de un lugar radica en conocer cuál es el significado de su nombre. En el caso de Huasca, este es una apócope de la palabra náhuatl Huascazaloya, que significa "lugar de regocijo o alegría". Otras posibles fuentes del origen lingüístico de Huasca son Cuachqetzaloyan, "lugar de agua", aunque esta palabra tiene otro 


\section{Journal of the Academy $|148|$}

significado "lugar donde se hacen preciosas mantas de algodón" (Gobierno del Estado de Hidalgo, 2016).

Esta localidad también hace uso del lema "lugar donde inicia la magia" como una forma de convertirse en una mercancía singular. Esto responde a que Huasca de Ocampo fue el municipio pionero dentro del programa Pueblos Mágicos del gobierno federal en 2001,-aunque para el 2020 son ya 121 las localidades que participan- sólo Huasca puede reclamar la primicia. Tal como lo define la propia Secretaría de Turismo Federal, este nombramiento fue otorgado a esta población por:

Pintoresco, sencillo y sobre todo estratégico, Huasca es un punto de partida perfecto para explorar las ex haciendas de beneficio, los bosques de oyamel, las presas, las formaciones rocosas y una joya natural que sobresale entre las otras: los Prismas Basálticos. Huasca de Ocampo ha atraído con su magia a personalidades como Humboldt, Melchor Ocampo y Romero de Terreros (Secretaría de Turismo, 2019).

Como podemos ver, la "mercancía" turística que es ofertada por la dependencia federal no sólo incluye lugares y actividades, sino personas que pasaron alguna etapa de su vida en dicha localidad, y que, con su presencia, suman a la candidatura mercantil y la singularidad de este sitio turístico. Este es el caso de Melchor Ocampo, político liberal mexicano, conocido además de su participación en el gobierno de Juárez por su epístola que era leída durante los matrimonios civiles.

La razón de que esta población del estado de Hidalgo lleve el nombre de un político michoacano consiste en que este personaje fue desterrado de su estado natal el 27 de abril de 1853, situación que lo lleva a radicar en Tulancingo, sin embargo, se sabe que pasó algún tiempo de este exilio en Huasca (Ruiz, 2000).

Melchor Ocampo es una figura que ha perdido importancia histórica y política ocupando un lugar secundario en los recuentos estatales sobre México. Sin embargo, constituye una figura fascinante que fue resaltada en el libro de Taibo "Patria" sobre el imperio de Maximiliano y su caída (Taibo II, 2017), pero también este personaje era un notable escritor y polemista. En la recopilación "Obras Completas, Tomo I, Polémicas Religiosas" este hombre de posturas liberales defendió al Estado laico mexicano. La capacidad argumentativa de Ocampo resulta notable, especialmente en la polémica con un "sacerdote" sobre la necesidad de que el Estado lograse terminar con todas las prácticas corporativas que perpetuaban la pobreza. 
A los pecados, no a los bienes se contrae vuestra potestad, puesto que para aquellos y no para éstos se os dieron las llaves del reino de los cielos...Los bienes temporales, caducos y miserables, tiene sus jueces propios, que son los Reyes y Príncipes de la tierra ¿Por qué querer invadir los límites extraños? ¿Por qué extender la hoz a mies ajena? (Ocampo, 1900, p. 331).

Para Ocampo, la libertad de elección de los individuos era uno de los principios generales de la convivencia humana que únicamente el Estado podía garantizar frente a las distintas creencias y credos. Este político mexicano no pedía la desaparición de la iglesia católica, sino el derecho de cada individuo por decidir sobre sus creencias y gozar de servicios básicos, temas fundamentales en la construcción de los estados modernos (Ocampo, 1900).

Pese a estar en el nombre de la localidad (Huasca de Ocampo) y de ser mencionado en la declaratoria como Pueblo Mágico para esta localidad, no existe ningún tipo de celebración respecto a este personaje organizada por las autoridades municipales o turísticas (su natalicio, muerte, etcétera), así como tampoco ha existido un intento por documentar y señalar los lugares donde este político mexicano habitó en su paso por este lugar. Incluso en una de las páginas que promocionan al pueblo mágico de Huasca (huascapueblomagico.gob.mx) no se considera a Melchor Ocampo entre los personajes ilustres, habiendo nombres como Maximino Martínez Martínez (profesor normalista y botánico autodidacta), Héctor Rangel Esquivel (médico), Francisco Chiapa (educador y militar) y Clemente Vergara (educador y quién recibió en 1869, el nombramiento de "El Ciudadano Distinguido de Huasca").

Esto concuerda con el lugar secundario que la historia nacional "oficial" ha conferido a este personaje, pero contrasta con el realce que el mismo programa Pueblos Mágicos hace de la "cuna" de personajes de primera importancia, incluso otorgar dicha denominación a poblados como Magdalena de Quino, Sonora, por ser el lugar de nacimiento de un político que fue candidato a la presidencia de México y miembro del Partido Revolucionario Institucional: Luis Donaldo Colosio.

Lo anterior refleja la existencia de dos relatos de la vida cotidiana en Huasca. La versión creada a partir de lo que las autoridades desean que la comunidad refleje ante la vista perpetua de sus visitantes, y qué se convierte en objeto para el intercambio. Y la versión auténtica de la gente, pero que puede no cumplir las expectativas de lo que los turistas desean como objeto de consumo. En este sentido, se considera que el discurso de la magia como factor detonante en 


\title{
Journal of the Academy $|150|$
}

el turismo de los pueblos radica en un reconocimiento no solo de lo tangible. Va más allá y abarca aquello que es susceptible de maravillar a sus visitantes a través de aquello que no pueden tocar, pero sí sentir y vivir. No obstante, muchas veces la "magia" de ciertas comunidades al considerarse no lo suficientemente impresionante a los ojos de los turistas, busca modificarse a modo, aunque ello no vaya acorde a la realidad histórica y cultural de la comunidad.

\section{Los prismas basálticos: creando la imagen de México}

\begin{abstract}
"No soy capaz de decirte cuán feliz me siento en esa parte del mundo; me he acostumbrado ya de tal manera al clima que me parece no haber vivido en Europa: solamente aquí es realmente verde el mundo; el cielo estrellado ofrece el espectáculo más espléndido; no puedo expresarte todo lo feliz que me encuentro en esa parte del mundo; quizá no hay ningún país en todo el mundo donde se pueda vivir tranquila y apaciblemente como en las colonias españolas" (Humboldt, citado en Cuesta, 2008: 29).
\end{abstract}

Los prismas basálticos de Santa María Regla no sólo tienen importancia, por sus excepcionales características geológicas y su extraordinaria belleza como paisaje natural, también han sido fundamentales en la construcción social de la imagen de México desde el siglo XVIII. Esto fue posible por el trabajo de otro personaje histórico que estuvo presente en Huasca de Ocampo: el alemán Alexander von Humboldt. A continuación, veremos quién era este personaje y su relación con este lugar.

Alexander von Humboldt (1769-1859) -cuyo nombre completo es Friedrich Wilhelm Heinrich Alexander Freiherr von Humboldt, - nació en Berlín, fue hijo de un oficial prusiano y de una mujer rica. La curiosidad científica de este personaje se nutrió de las ideas de la Ilustración mismas que transformaron la relación de los hombres con la naturaleza, ahora mediada por la ciencia y la confianza en la capacidad del conocimiento para modificar la realidad (Cuesta, 2008).

La herencia materna le permitió a Humboldt planear una larga expedición por el continente americano, desde Sudamérica hasta los Estados Unidos. El 22 de marzo de 1803 Humboldt arribó al puerto de Acapulco. La intención de este autor en el territorio de la Nueva España (ahora México) era generar una cartografía, pero también recolectar y clasificar plantas, animales, muestras geológicas, las costumbres de los habitantes, viejas civilizaciones, 


\section{Journal of the Academy $|151|$}

agricultura, división política, comercio, rentas y la defensa militar. Es decir, tenía interés en registrar todo lo que encontrara en su camino. El libro sobre este viaje tenía el título original de: Ensayo político sobre el reino de la Nueva España con Atlas físico y geográfico, fundado sobre observaciones astronómicas, medidas trigonométricas, y nivelaciones barométricas, quedando finalmente como Ensayo político de la Nueva España (Humboldt, 1827).

El trabajo de Humboldt es significativo porque representa el primer gran intento por registrar de manera sistemática y ordenada (científica) las características naturales, geográficas, sociales, históricas y económicas de la región que ahora llamamos México, pero también porque sus observaciones sobre la sociedad y las civilizaciones prehispánicas fueron vistas bajo un método comparativo que le permitió analizarlas a la par de las "grandes civilizaciones" como la egipcia o la griega (Humboldt, 1827).

Con esto último, Humboldt reconstruyó la idea que el mundo occidental tenía sobre esta colonia del imperio español; de un lugar con una cultura "bárbara" a un conjunto de grandes civilizaciones que compartían rasgos con el pasado de Europa y Asia. Como veremos, los trabajos de Humboldt serían fundamentales para el futuro nacionalismo del estado mexicano post independentista y postrevolucionario.

Ante todo, Humboldt es el primer gran turista del continente americano y como le pasa a todos los que viajan, muestra una particular fascinación por ciertos lugares. Este fue el caso de México, sobre el que hizo grandes alabanzas a lo largo de su libro: “...Apenas hay un punto en el globo, en donde las montañas presenten una constitución tan extraordinaria como las de Nueva-España..." (Humboldt, 1827: 62). Los escritos de Humboldt fueron centrales para renovar la imagen del territorio mexicano frente al público europeo, pero principalmente, frente a las elites intelectuales mexicanas (Uribe, 2008); podemos decir que las obras de este autor alemán constituyen uno de los proto-elementos que ayudarían a la conformación de la idea de una nación mexicana, que a la luz de estos escritos aparecía rica en recursos naturales, culturales y sociales; la investigación de Humboldt podría ser considerada una de las bases sobre las que se construiría después la idea de la nación mexicana. 


\section{Los prismas basálticos vistos por Humboldt}

Humboldt publicó un libro titulado "Vues des Cordillères, et monumens des peuples indigènes de l'Amérique" Sitios de las Cordilleras y monumentos de los pueblos indígenas de América, entre otras regiones del continente americano, este autor recorrió México y, muy particularmente, las cascadas de Santa María Regla, a las que él nombra como las "Rocas Basálticas de la Cascada de Regla”. Es interesante mencionar que la conocida ilustración de los prismas sólo está disponible en la edición francesa del libro de Humboldt (1810), pero no en la primera edición en español (Humboldt, 1878).

En la versión española de la obra de Humboldt (1878), el primer capítulo está dedicado a las “Rocas Basálticas y Cascada de Regla". Humboldt utiliza estas formaciones para analizar el origen de las distintas regiones del continente e incluso adelanta la que se sería la explicación más aceptada sobre la formación de los prismas (Humboldt, 1878: 29).

La descripción del sitio resulta de gran importancia por ser la primera que se hizo sobre la zona. La imagen dibujada por el mismo Humboldt difundió en toda Europa una belleza natural que era desconocida, incluso, por la gran mayoría de los habitantes de la Nueva España (Humboldt, 1878: 29-30).

Al igual que sucede con Melchor Ocampo, en la población de Huasca no existe ningún tipo de celebración o conmemoración respecto al paso de Humboldt por esta tierra, esto a pesar de que los prismas basálticos son parte de los atractivos más promocionados sobre esta localidad. La imagen y presencia de este personaje podría permitir una ampliación del contexto mercantil donde este lugar podría posicionarse, atrayendo a personas interesadas en cuestiones geológicas, turismo de naturaleza y la vida misma de Humboldt: uno de los científicos más reconocidos en la historia moderna.

Los prismas basálticos son mercancías por metamorfosis, objetos que fueron observados y conservados por su importancia científica y estética, pero que con el crecimiento de la actividad turística y el desarrollo de programas como el referido programa Pueblos Mágicos fueron transformados en uno de los principales atractivos naturales en Huasca de Ocampo. No obstante, el contexto mercantil turístico donde han sido inscritos es exclusivamente el de su turistificación contemplativa: los visitantes recorren un puente que atraviesa el río donde se 


\section{Journal of the Academy $|153|$}

encuentran los Primas u observan desde la hacienda la cascada de la Rosa. No existe una integración de los prismas a una historia cultural o social de la misma localidad, como si estas piedras nunca hubieran formado parte de la vida de los locales.

\section{Pedro Romero de Terreros (El conde de Regla)}

Pedro Romero de Terreros nació el 28 de junio de 1710 en San Salvador Cortegana, en la provincia de Andalucía, España. Como muchos jóvenes españoles de su época, Pedro Romero de Terreros buscó emigrar a América buscando la fortuna que prometía el nuevo continente. Con el tiempo, la riqueza que este personaje llegó a acumular, le valdría ser reconocido como uno de los hombres más acaudalados de la época colonial española y posiblemente del mundo.

Don Pedro Romero de Terreros llegó a México, para trabajar con su tío Juan Vázquez en los negocios de este. Desde el inicio, el joven Pedro mostró gran diligencia y capacidad de trabajo convirtiéndose eventualmente en el administrador general y en uno de los dos ejecutores del testamento de su tío, lo que parece corroborar la imagen de confiabilidad que despertaba en los demás. Al tiempo de su arribo, asumió el "Don”, término reservado para reyes y sus parientes cercanos, pero posteriormente también para miembros de la iglesia, militares e hidalgos. Don Pedro Romero vivió en lo que posteriormente sería México entre 1730 y 1781, nunca regresó a su país natal (Boorstein, 2003). Su trabajo comenzó a dar sus frutos y para 1725 Pedro Romero fue aceptado en la orden militar de Calatrava, honor solo conferido a los hombres con grandes recursos financieros. Ese mismo año, el arzobispo de México le dio el título honorífico de "Padre de los desvalidos y fiel apoyo de Religión", lo que también estaba destinado a las personas ricas que contribuían con extensos recursos para obras de la iglesia.

La llegada de Pedro Romero de Terreros a Pachuca y Real del Monte se encuentra muy relacionada a José Alejandro Bustamante, dueño de la Veta Vizcaína. En un primer momento, Bustamante invitó a Romero de Terreros en calidad de inversionista (aviador), principalmente, para sacar el agua de las minas. Los trabajos para drenar las minas muestran la tenacidad y determinación de Pedro Romero de Terreros. La recuperación de las minas se prolongó entre 1740 a 1762, para el tercer año, Bustamante y Romero eran socios en partes iguales, utilizando un método distinto a los que utilizó Isidro Rodríguez de Madrid: comenzaron a abrir "contraminas", es decir túneles por debajo de las minas que permitieran que el agua fluyera por ellas. Esto resultó un método más caro, pero que al final fue más efectivo (Boorstein, 2003). 
La muerte de José Alejandro Bustamante en 1750 convirtió a Pedro Romero de Terreros en el dueño de la Veta Vizcaína, no sin algunas dificultades y pleitos legales con familiares de Bustamante u otros inversionistas. Pedro Romero continuó invirtiendo entre 1750 y 1766 grandes cantidades para lograr conectar (un túnel de2352 metros) y drenar todas las minas de la Veta Vizcaína; para septiembre de 1762, había gastado 1428706 pesos. No existe información precisa sobre el año en que Romero de Terreros comenzó a obtener grandes ganancias de sus minas, pero esto ocurrió entre 1749 y 1759, se tiene el dato de que en 1759 registró 60000 marcos de plata (480000 pesos) en la caja oficial de Pachuca (Boorstein, 2003).

Los registros que se tienen muestran que fue a partir de 1751 cuando se produjo un incremento significativo en la producción de plata. El trabajo de Hausberger sobre los libros de cargo, nos permitió saber que entre el 57 y el 76 por ciento de la producción de plata en la región de Pachuca-Real del Monte pertenecía a Romero de Terreros (Hausberger, 1997; Boorstein, 2003).

Sobre Romero de Terreros podemos decir que sucede lo mismo que con los dos personajes anteriores mencionados, no existe ningún tipo de celebración o intento de resaltar su presencia en la región. Esto a pesar de que este personaje vivió la mayor parte de su vida en la localidad y su contribución fue fundamental para entender la zona rural que rodea a la población de Huasca de Ocampo, dado que las haciendas de este personaje fueron las grandes divisoras de la tierra durante una época.

Una posible explicación de por qué las administraciones municipales han preferido no utilizar la candidatura mercantil que podría proporcionar a Huasca la presencia de Humboldt o Romero de Terreros la proporciona Mario Velázquez (2013) al analizar la creación de la política turística de Pueblos Mágicos: esta buscaba reinsertar ciudades y edificaciones coloniales y religiosas que no eran parte del relato nacional de los gobiernos revolucionarios nacionalistas (Velázquez, 2013, p. 106).

Los gobiernos municipales de Huasca de Ocampo eran afines al Partido Revolucionario Institucional (PRI) durante el reconocimiento de esta población como parte del programa Pueblos Mágicos. Esto podría explicar su reticencia a resaltar símbolos coloniales que eran relacionados con un periodo de dominación extranjera dado que estos personajes eran parte de 


\section{Journal of the Academy $|155|$}

esa época (Velázquez, 2013). Por una razón similar, aunque de un signo político radicalmente contrario, el siguiente personaje que pasó por Huasca de Ocampo no ha recibido ningún tipo de mención en el turismo y la historia local: León Trotsky.

\section{León Trotsky (Lev Davídovich Bronstein)}

"Huasca es un buen escondite para políticos" Abuela Gila (Ruiz, 2016)

Pocas personas lo saben, pero uno de los personajes más sobresalientes de la historia mundial del siglo XX vivió en Huasca de Ocampo. Nos referimos a Lev Davídovich Bronstein mejor conocido como Trotsky. Este hombre fue uno de los actores más relevantes durante la Revolución Soviética (1917-1923) donde formó parte del Comité Central bolchevique. Posteriormente fue nombrado "comisario del pueblo "y presidente de la Junta Suprema de Defensa. En esta tarea mostró una gran capacidad organizativa: en dos años de la nada formó el Ejército Rojo con más de 2 millones de efectivos. Las luchas internas dentro del Politburó terminaron transformando a Trotsky de un héroe nacional en "enemigo de la revolución", acusado de cometer serias violaciones a la disciplina del partido, fue condenado primero a ser deportado a Kazajistán y exiliado de la Unión Soviética en 1929.

León Trotsky fue recibido en México, en gran parte, por la presión de artistas e intelectuales del país, principalmente de Diego Rivera. El gobierno de Lázaro Cárdenas aceptó concederle el estatus de refugiado.

La presencia de este personaje en México no fue ignorada por los otros países, la Unión Soviética ejerció presión diplomática para la entrega de su ciudadano acusado de varios delitos. Adicionalmente, distintos grupos políticos conservadores al interior de México pedían su inmediata expulsión. Una dificultad adicional eran los posibles atentados contra su vida. Por esta razón, las autoridades mexicanas destinaron un pequeño cuerpo de seguridad y como una de las medidas precautorias, este personaje cambiaba su residencia a distintas partes de la ciudad de México o sus alrededores. En uno de estos cambios de domicilio, se instaló tres meses en una discreta casa que miraba hacia la ex hacienda de San Miguel Regla. A este respecto María Ruíz, cronista de Huasca de Ocampo, recuperó una historia familiar que nos permitió saber que León Trotsky vivió en una casa conocida como "la isla” junto a la Presa San Antonio: 
En algún momento de entre 1937 y 1940, León Trotsky, fundador del ejército rojo y gran artífice de la Revolución Rusa, pasó tres meses escondido en el municipio de Huasca. Lázaro Cárdenas lo encargó con quien había sido el gran terrateniente de la región José Landeros, pues era perseguido por los fanáticos de Stalin, que lo habían condenado a muerte y, por católicos recalcitrantes que le odiaban por ateo...Desde niña conozco la historia, la escuché en la cocina de la casa, entre las sonrisas socarronas de mi abuela y su hermana, mi tía abuela Con. Al parecer, León Trotsky era siempre acompañado por dos guardaespaldas, Sisto y Casas, de apodo Casitas...Trotsky, por otro lado, era bajito, blanco, de ojos azules y usaba una barba, que mi tío abuelo Carlos Licona calificó como "piocha", me dijo también que luego sus amigos y él se dejaron "la piocha". Por ese entonces trabajaba en el taller de alfarería de su padre que estaba en la Casa Azul y uno de esos días, entró un forastero, más gordo que corpulento, de extraños ojos saltones. Como ellos estaban pintando jarros, el visitante les preguntó si le permitían pintar uno, a lo que le dijeron que sí. Dice mi tío que cogió el pincel y de un solo trazo dibujo un venado blanco y lo firmó con el nombre de Diego Rivera. Como por ese entonces ninguno de los presentes sabía quién era, pues no conservaron el dicho jarro... Frida también fue a visitar a Trotsky, en la última morada de José Landeros, donde los singulares personajes pasaron unos días...Mi tía abuela Gila me dijo que en aquellos años no había prácticamente autos, y aunque Trotsky tenía el propio, solía viajar también en los coches que prestaban servicio público en los que se viajaba como sardinas, o que podía montar a caballo y desde luego caminar, pues nunca solía transportarse de un solo modo... (Ruiz, 2016).

El caso de León Trotsky ilustra claramente el argumento antes mencionado de Velázquez (2013), en la planeación turística están presentes componentes ideológicos provenientes de los actores que crean esta política, por lo que ciertos elementos de la historia de una localidad son considerados como contrarios al tipo de imagen social (y turística) que una localidad busca presentar. No deja de ser significativo que, a pesar del tiempo transcurrido desde la muerte de este personaje, la desaparición de la Unión Soviética y la nula presencia en México de un partido comunista, la historia de Trotsky como un posible atractivo turístico que transfiera singularidad a este Pueblo Mágico no sea considerado.

\section{Ex Hacienda Santa María Regla}

La hacienda de Santa María Regla fue construida por Pedro Romero de Terreros entre 1760 y 1762. De la estructura original se conserva gran parte de su casco, los arcos que en un inicio eran parte de los patios y los hornos donde era procesada la valiosa plata. En la actualidad, la hacienda funciona como un hotel y brinda recorridos por las instalaciones. La hacienda conduce a la cascada de la Rosa Pintada, el lugar dibujado por Alexander von Humboldt (Santa María Regla hacienda-hotel, 2018). 
Las haciendas no solo eran unidades económicas. Herbert Nickel en su libro "Morfología social de la hacienda mexicana" estudió estas unidades productivas, interesándose por encontrar una definición clara. Para ello mostró su evolución, pasando de formas mixtas de producción hasta terminar convertidas en unidades capitalistas casi industrializadas y altamente tecnificadas, con mano de obra que había pasado por un proceso de especialización en distintas funciones. La hacienda tenía tres componentes estructurales: 1) permitían la explotación de los recursos naturales de determinada zona; 2) control sobre la mano de obra; 3) el dominio de los mercados locales y regionales (Nickel, 1988). Algunas características "secundarias" de las haciendas son: a) selección de productos, b) el monto de la producción, c) el origen del capital, d) el arrendamiento, e) el ausentismo de los dueños, f) la autosuficiencia económica, g) la proporción de autoconsumo, h) la división del trabajo, i) infraestructura física y j) técnicas agrícolas (Wobeser, 1989: 53-54). Como lo muestra el trabajo de Gisela Wobser (1989), la combinación de estos elementos que la investigadora llamó como secundario, determinaba la existencia y funcionamiento de distintos tipos de haciendas: algodonera, cafetalera, henequenera, ganadera, pulquera, entre otras.

El nombre de la hacienda de Santa María Regla tiene atrás una serie de historias que convergen en la capilla consagrada a la Virgen de Regla y en Pedro Romero de Terreros. La primera tiene que ver con la imagen venerada. La leyenda inicia con san Agustín, -Aurelio Agustín de Hiponia- uno de los teólogos más importantes para el cristianismo, autor de libros fundamentales para la evolución de esta fe, como La ciudad de Dios, Soliloquios y Confesiones.

En la última etapa de su vida, en 391 D.C., san Agustín fue ordenado sacerdote en Hiponia con la encomienda de enseñar el cristianismo a las personas de esta ciudad. Por indicaciones de un ángel, el santo mandó tallar la estatua que tiene una estatura de 62 centímetros. Respecto al nombre de "Regla" existen dos explicaciones. La primera sencillamente hace referencia a un lugar, donde la Virgen tiene su templo en un lugar que anteriormente se llamaba así, es decir, Regla. La segunda parte del nombre se encuentra relacionada a San Agustín, la regla, haría referencia a las normas que esté redactó para organizar la vida de los monjes en el monasterio de Tagaste, en el norte de África. 


\section{Journal of the Academy $|158|$}

Las versiones sobre lo que sucedió con la imagen de la Virgen de Regla difieren. Un relato es que san Agustín, falleció el 28 de agosto del año 430 durante un sitio para tomar la ciudad. A su muerte, la figura de la Virgen de Regla es ocultada. Una segunda historia es que el sitio a la ciudad por parte de los vándalos tuvo lugar trece años después de la muerte de San Agustín (443), los monjes agustinos huyen a España con la imagen de la virgen, fundando el monasterio de Regla con la imagen mirando al mar.

La imagen permaneció en el Monasterio de Regla hasta el 711 (siglo VIII) cuando llegó a esta región la toma de los moros a España. Los monjes decidieron ocultar la imagen con algunos de sus ornamentos para evitar que estos fueran robados o destruidos por los invasores. Lo que sucedió después, constituye la historia-leyenda sobre cómo fue recuperada la imagen de la virgen que permaneció oculta por 700 años (Probert, 2011; 182).

La Virgen de la Regla, probablemente por el lugar donde fue localizada, es la patrona de los marineros, su fiesta es el 8 de septiembre. Esto tiene importancia en nuestro relato de historias relacionadas. Al acudir Pedro Romero de Terreros a Cádiz, -en búsqueda de los documentos que le permitieran emigrar a la Nueva España-, visitó Chipiona y ahí encontró la Ermita de la Virgen Negra de Santa María de Regla. La historia sobre el origen del culto a la virgen y su patronazgo sobre la gente que se embarcaba al mar debieron de impresionar al próximo pasajero, que decidió jurarle veneración y adquirió una imagen al óleo que lo acompañaría hasta el final de su vida. Esta es la razón por la que tanto la hacienda San Miguel Regla como Santa María Regla, tienen este nombre. En esta última se construyó una capilla en su honor, que todavía es posible visitar.

\section{La vida turística (mercantil) de los bienes de Huasca de Ocampo. A modo de conclusión}

El municipio de Huasca de Ocampo es una población que ha ocupado una posición significativa en la historia nacional, ya sea por los personajes que en ella han estado (Melchor Ocampo, Romero de Terreros, Alexander von Humboldt y León Trotsky), pero también por sus productos (mineros y agrícolas) así como por sus edificaciones (iglesias y haciendas). Sin embargo, la candidatura mercantil de esta localidad en tanto producto turístico del programa federal Pueblos Mágicos, no fue elaborada aludiendo a las características singulares de la localidad sino al contexto mercantil de la política pública que fomentó y promovió este tipo específico de turismo en México. Es decir, se buscó resaltar una serie de características vagas 


\section{Journal of the Academy $|159|$}

y homogenizadas respecto a "lo mexicano" y "lo típico" que se traducían en mejoras de las calles, la mejora de fachadas, la venta de comida "mexicana" y negocios que ofrecieran "artesanías" sin un lugar claro de origen. Son diversas las afirmaciones respecto al origen de la denominación de Huasca de Ocampo como Pueblo Mágico. En primera instancia se alega que es gracias a sus inigualables atractivos naturales, entre los que destacan los prismas basálticos; así como su riqueza cultural y arquitectónica reflejada en las haciendas que aún perduran y que le brindan un aire colonial (SECTUR, 2014), aunado a ello resalta la calidez de su gente.

Otras posturas (López, L., Valverde C., Fernández, A., 2015; Valverde, V., Enciso, G., 2014) aseguran que la designación de Huasca como primer Pueblo Mágico fue una decisión arbitraria, basada principalmente en la existencia de grupos de poder en dicho municipio y vinculados a familias poderosas de Pachuca, buscando en primera instancia beneficiarse económicamente con la denominación del municipio hidalguense. Por otro lado, refieren que la manera en la cual se estructuró el programa Pueblos Mágicos tuvo que ver con beneficiar a los grupos poder político más que a las comunidades. De acuerdo con dichos autores, la designación de los pueblos mágicos ha sido parcial y arbitraria, cómo tal es el caso de Huasca de Ocampo; no obstante, ello no demerita la belleza del lugar y los atractivos naturales y culturales con los que cuenta. Cabe destacar que la comunidad de Huasca tampoco tiene claro cuáles fueron los fundamentos para que su comunidad fuera elegida como piloto del programa (López, L., Valverde C., Fernández, A., 2015).

\section{CONCLUSIONES}

En otras palabras, el programa Pueblos Mágicos no buscaba fomentar (es decir apoyar con recursos para cultura, investigación o restauración) las características que volvían única a una población (y un producto singular que era colocado en el mercado), sino promover (exhibir mediante canales de propaganda y comerciales) una mercancía por metamorfosis que resultara familiar y accesible para todos los consumidores, por lo cual, se alentó la producción de una mercancía homogenizada.

La candidatura mercantil de Huasca de Ocampo presentaba una diversidad y complejidad histórica que la misma población local todavía no ha logrado resolver y clasificar; la herencia colonial, de riqueza y el presente de una economía que tiende a los servicios (turísticos) no ha permitido una discusión local que permita conferir un lugar a estos personajes históricos que 


\section{Journal of the Academy $|160|$}

construyeron o transitaron por esta población. Como hemos visto, la presencia de estos personajes no ha generado ningún tipo de reconocimiento por parte de la población local, esto genera una oportunidad para que las políticas de turismo no sean únicamente una forma de convertir lugares y festividades en una candidatura mercantil sino de contribuir a la discusión y reapropiación local de la historia y la cultura.

Las haciendas, bienes que se convirtieron dentro del turismo en mercancías por metamorfosis, al ser privatizadas han sido aisladas del contexto social, productivo y ambiental que las rodea; concentrando sus ganancias en los dueños. Esto genera el distanciamiento social del patrimonio material e inmaterial que representan estos lugares para las comunidades. Sin embargo, este no es el único camino: las haciendas y el gobierno municipal podrían generar programas de turismo rural que activaría la agricultura, producción de artesanías, gastronomía, festividades, etcétera. Esto propiciaría una reintegración de las haciendas a su entorno y con ello, la repartición de los beneficios.

\section{REFERENCIAS BIBLIOGRÁFICAS}

Appadurai, A. (1991). Las mercancías y la política del valor. En Arjun Appadurai. La vida social de las cosas. México: Editorial Grijalvo.

Boorstein, E. (2003). The Silver King. The remarkable life of the Cound of Regla in Colonial Mexico. USA: University of New Mexico. Boortein, E. La Hacienda de Hueyapan, 15501936.

Burns. (2004). The Spirits of America. A social History of Alcohol. USA: Temple University Press.

Cowan, B. (2005). The Social Life of Coffee. Englad: Yale University Press.

Cuesta, D. M. (2008). "Humboldt, viajero geográfico" en Cuesta, M., Rebok, S. Alexander von Humboldt. Estancia en España y viaje americano. España: Real Sociedad Geográfica.

Diario Oficial de la Federación. (1926). Resolución en el expediente de dotación de tierras promovida por vecinos del pueblo de Huasca Saloya, o Huasca de Ocampo, Estado de Hidalgo. Jueves 27 de mayo de $1926 .<$ Recuperado de: http://www.dof.gob.mx/index.php?year=1926\&month=05\&day=27> $>\quad$ Fecha de consulta: 24 de noviembre de 2020).

Dood, N. (2014). The Social Life of Money. USA: Princeton University Press.

Gobierno del Estado de Hidalgo. 2016. Enciclopedia de los municipios de Hidalgo: Huasca de Ocampo. México. <Recuperado de: http://siieh.hidalgo.gob.mx/files/huasca.pdf > (Fecha de consulta: 20 de noviembre de 2020). 
Hernández, H., G. (2017). "Tatsugoro Matsumoto y la magia de las jacarandas en México". Arquine. Revista digital. 2 de marzo 2017. <Recuperado de: http://www.arquine.com/tatsugoro-matsumoto-y-la-magia-de-las-jacarandas-en mexico/> (Fecha de consulta: 16 de abril de 2018).

Haciendas de México. (2018). Hacienda San Juan Bautista Hueyapan. <Recuperado de: http://haciendasdemexico.org/project/hacienda-san-juan-bautista-hueyapan/> (Fecha de consulta: 21 de febrero de 2018).

Historia. (s.f.). Huasca de Ocampo. Recuperado de: <Huasca de Ocampo - Historia (huascapueblomagico.gob.mx)> (Fecha de consulta: 23 de noviembre 2020).

Humboldt, A. (1827). Ensayo político sobre el Reino de la Nueva España. Viaje a las regiones equinocciales del nuevo continente hecho en 1799 hasta 1804. Francia: Imprenta de Paul Renouard.

Humboldt, A. (1878). Sitios de las Cordilleras y monumentos de los pueblos indígenas de América. España: Imprenta y librería Gaspar.

Jarquín, M. Origen y evolución de la hacienda en México, siglos XVI al XX

Maquet, J. (1986). La experiencia estética. España: Ediciones Celeste.

Marx, K. (1975). El capital. Crítica de la economía política. México: Siglo XXI.

Ocampo, M. (1900). Melchor Ocampo obras completas. Tomo I Polémicas religiosas. F. México: Vázquez Editor.

Probert, A. (1987). En pos de la plata. Episodios mineros en la historia hidalguense. Gobierno del Estado de Hidalgo. México: Colección Hidalguense.

Ruiz de la Barrera, R. (2000). Breve historia de Hidalgo. México: Fondo de Cultura Económica.

Ruiz, M. (2016). “Trotsky, Diego, Frida y mis abuelos”. El Sol de Hidalgo. (Fecha de consulta: 16 de enero de 2016).

Santa María Regla hacienda- hotel. (2018). Página oficial. <Recuperado de: http://www.haciendaderegla.com.mx/index.php/nosotros $>$ (Fecha de consulta: el 21 de febrero de 2018).

Secretaría de turismo (SECTUR). 2016. Diagnóstico del programa presupuestario Programa de desarrollo regional turístico sustentable pueblos mágicos. Sectur. México

Secretaría de turismo (SECTUR). (2019). Huasca de Ocampo, Hidalgo. Secretaría de turismo. <Recuperado de: https://www.gob.mx/sectur/articulos/huasca-de-ocampohidalgo?idiom=es $>$ (Fecha de consulta: 19 de noviembre de 2020).

Taibo II, P. (2017). La gloria y el sueño que forjó una patria. Volumen I. México: Editorial Planeta. 
Trotsky, L. (1937. En México. Carta. Librodot.

Uribe, S. A. (2008). "Alexander von Humboldt en Nueva España y el Real Seminario de Minería de México". En Cuesta D. M., Rebok. S. Alexander Von Humboldt. Estancia en España y viaje americano. España: Real Sociedad Geográfica.

Valverde, V., Enciso, G. (2014). La magia de los pueblos: ¿atributo o designación? Turismo cultural en México. Academia XXII. UNAM.ISSN: 2007-252X. Primera época · Año 4. Número 7. México. Agosto 2013-Enero 2014 . pp 11-25. DOI: http://dx.doi.org/10.22201/fa.2007252Xp.2013.7.43000

Velázquez, G. M. (2010). Las luchas verdes. Los movimientos ambientalistas de Tepoztlán, Morelos y el Cytrar en Hermosillo, Sonora. México: El Colegio de Sonora.

Wobeser, G. (1989). La formación de la hacienda en la época colonial El uso de la tierra y el agua. México: Universidad Nacional Autónoma de México, Instituto de Investigaciones Históricas.

Velázquez, G. M. (2013). La formulación de las políticas públicas de turismo en México. El caso del programa federal "Pueblos Mágicos" 2001-2012. Diálogos Latinoamericanos, (21). Pp. 89-110. ISSN: 1600-0110

Velázquez, G.;Labra, A. (2015). Logros y problemáticas de los Pueblos Mágicos del Estado de Hidalgo. Revista Semestral de Estudios Regionales, 4 (julio-diciembre): 46-60.

Velázquez García Mario y Balslev Clausen Helene. (en prensa). Las políticas de turismo en México. Benemérita Universidad Autónoma de Puebla. México. 